\title{
Solution to the pycnometer challenge
}

\author{
Olaf Rienitz • Axel Pramann • Carola Pape
}

(C) Springer-Verlag Berlin Heidelberg 2013

The winner of the pycnometer challenge (published in volume 405, issue 17) is:

Enea Pagliano, Ottawa, Canada.

The award entitles the winner to select a Springer book of his choice up to a value of $€ 100$.

Our Congratulations!

\section{Solution}

(1) The inner volume of the pycnometer, $V_{\mathrm{p}}$, is readily obtained from the mass of pure water, $m_{\mathrm{w}}$, it can hold (and the density of that water, $\rho_{\mathrm{w}}$ ). The actual mass can be calculated from the air buoyancy correction factor $K_{\mathrm{w}}$ of the water (using the corresponding density of air, $\rho_{\text {airl }}=1.18073 \mathrm{~kg} \mathrm{~m}^{-3}$ ), and the difference between the apparent masses of the filled and empty pycnometer $\left(m_{\mathrm{p}+\mathrm{w}}^{\prime}\right.$ and $m_{\mathrm{p} 1}^{\prime}$, respectively).

$V_{\mathrm{p}}=\frac{m_{\mathrm{w}}}{\rho_{\mathrm{w}}}=\frac{K_{\mathrm{w}} \times\left(m_{\mathrm{p}+\mathrm{w}}^{\prime}-m_{\mathrm{p} 1}^{\prime}\right)}{\rho_{\mathrm{w}}}$, where $K_{\mathrm{w}}=\frac{1-\rho_{\mathrm{air} 1} / \rho_{\mathrm{cal}}}{1-\rho_{\mathrm{air} 1} / \rho_{\mathrm{w}}}$

The density of the TMAH solution is determined in a similar way, using the volume of the pycnometer, $V_{\mathrm{p}}$, and the apparent masses of the filled and empty pycnometer $\left(m_{\mathrm{p}+\mathrm{s}}{ }^{\prime}\right.$ and $m_{\mathrm{p} 2}^{\prime}$, respectively), in addition to the buoyancy correction factor of the TMAH solution, $K_{\mathrm{s}}$.

$V_{\mathrm{p}}=\frac{m_{\mathrm{s}}}{\rho_{\mathrm{s}}}=\frac{K_{\mathrm{s}} \times\left(m_{\mathrm{p}+s}^{\prime}-m_{\mathrm{p} 2}^{\prime}\right)}{\rho_{\mathrm{s}}}$, where $K_{\mathrm{s}}=\frac{1-\rho_{\mathrm{air} 2} / \rho_{\mathrm{cal}}}{1-\rho_{\mathrm{air} 2} / \rho_{\mathrm{s}}}$

This article is the solution to the Analytical Challenge to be found at http://dx.doi.org/10.1007/s00216-013-7012-0

O. Rienitz $(\bowtie) \cdot$ A. Pramann $\cdot$ C. Pape

Physikalisch-Technische Bundesanstalt (PTB), Bundesallee 100,

38116 Braunschweig, Germany

e-mail: olaf.rienitz@ptb.de
By combining these two expressions (thus eliminating $V_{\mathrm{p}}$ ), we can obtain the conventional expression for the density of the TMAH solution, $\rho_{\mathrm{s}}$ :

$$
\begin{aligned}
& \frac{K_{\mathrm{w}} \times\left(m_{\mathrm{p}+\mathrm{w}}^{\prime}-m_{\mathrm{p} 1}^{\prime}\right)}{\rho_{\mathrm{w}}}=\frac{K_{\mathrm{s}} \times\left(m_{\mathrm{p}+s}^{\prime}-m_{\mathrm{p} 2}^{\prime}\right)}{\rho_{\mathrm{s}}} \\
& \rho_{\mathrm{s}}=\rho_{\mathrm{w}} \frac{K_{\mathrm{s}} \times\left(m_{\mathrm{p}+s}^{\prime}-m_{\mathrm{p} 2}^{\prime}\right)}{K_{\mathrm{w}} \times\left(m_{\mathrm{p}+\mathrm{w}}^{\prime}-m_{\mathrm{p} 1}^{\prime}\right)}
\end{aligned}
$$

The buoyancy correction factor for the TMAH solution, $K_{\mathrm{s}}$, is unknown at first, because the density of TMAH solution is still unknown. However, an estimated "starting" value of the density of the TMAH solution could be taken as $\rho_{\mathrm{s}, 0}=$ $1000 \mathrm{~kg} \mathrm{~m}^{-3}$. This yields the first estimate of the density, $\rho_{\mathrm{s}, 1}$ (note that $\rho_{\text {air } 2}=1.17990 \mathrm{~kg} \mathrm{~m}^{-3}$ is taken for the second experiment):

$$
\begin{aligned}
K_{\mathrm{w}} & =\frac{1-1.18073 / 8000}{1-1.18073 / 997.880}=1.0010369 \\
K_{\mathrm{s}, 0} & =\frac{1-1.17990 / 8000}{1-1.17990 / 1000}=1.0010336 \\
\rho_{\mathrm{s}, 1} & =0.997880 \mathrm{~g} \mathrm{~mL}^{-1} \times \frac{1.0010336 \times(15.1242-10.0348) \mathrm{g}}{1.0010369 \times(15.0216-10.0348) \mathrm{g}} \\
& =1.01841 \mathrm{~g} \mathrm{~mL}^{-1}
\end{aligned}
$$

Then, using this first estimate of $\rho_{\mathrm{s}}$, an improved air buoyancy correction factor, $K_{\mathrm{s}, 1}$, is calculated. This, in turn, results a yet better estimate of the density, $\rho_{\mathrm{s}, 2}$.

$$
\begin{aligned}
K_{\mathrm{s}, 1} & =\frac{1-1.17990 / 8000}{1-1.17990 / 1018.41}=1.0010123 \\
\rho_{\mathrm{s}, 1} & =0.997880 \mathrm{~g} \mathrm{~mL}^{-1} \times \frac{1.0010123 \times(15.1242-10.0348) \mathrm{g}}{1.0010369 \times(15.0216-10.0348) \mathrm{g}} \\
& =1.01839 \mathrm{~g} \mathrm{~mL}^{-1}
\end{aligned}
$$


Yet another iteration yields the density of TMAH, which is indistinguishable from the last iteration. Hence, we can state that the density of the TMAH solution is $\rho_{\mathrm{s}}=1.018$ $39 \mathrm{~g} \mathrm{~mL}^{-1}$.

(2) Neglecting the air buoyancy altogether yields a slightly different result that equals (within the number of digits) the result of the first iteration step, i.e., $\rho_{\mathrm{s}}=1.018$ $41 \mathrm{~g} \mathrm{~mL}^{-1}$.

(3) References [1] and [2] offer a much more elegant analytical solution which enables calculation of the density $\rho_{\mathrm{s}}$ in a single step. The weighing results of the empty and water-filled pycnometers can be written as follows:

$m_{\mathrm{p} 1}^{\prime}=m_{\mathrm{p}} \frac{1}{K_{\mathrm{p}}}=m_{\mathrm{p}} \frac{1-\rho_{\mathrm{air} 1} / \rho_{\mathrm{p}}}{1-\rho_{\mathrm{air} 1} / \rho_{\mathrm{cal}}}$

$m_{\mathrm{p}+\mathrm{w}}^{\prime}=m_{\mathrm{p}} \frac{1}{K_{\mathrm{p}}}+m_{\mathrm{w}} \frac{1}{K_{\mathrm{w}}}=m_{\mathrm{p}} \frac{1-\rho_{\text {air } 1} / \rho_{\mathrm{p}}}{1-\rho_{\text {air } 1} / \rho_{\mathrm{cal}}}+m_{\mathrm{w}} \frac{1-\rho_{\mathrm{air} 1} / \rho_{\mathrm{w}}}{1-\rho_{\text {air } 1} / \rho_{\text {cal }}}$

Note that $m_{\mathrm{w}}=\rho_{\mathrm{w}} V_{\mathrm{p}}$. By subtracting the above equations one can obtain the inner volume of the pycnometer, $V_{\mathrm{p}}$ :

$V_{\mathrm{p}}=\frac{m_{\mathrm{p}+\mathrm{w}}^{\prime}-m_{\mathrm{p} 1}^{\prime}}{\rho_{\mathrm{w}}-\rho_{\mathrm{air} 1}}\left(1-\rho_{\text {air } 1} / \rho_{\mathrm{cal}}\right)$

Likewise, weighing of the empty and sample-filled pycnometers can be described as follows:

$m_{\mathrm{p} 2}^{\prime}=m_{\mathrm{p}} \frac{1-\rho_{\mathrm{air} 2} / \rho_{\mathrm{p}}}{1-\rho_{\mathrm{air} 2} / \rho_{\mathrm{cal}}}$

$m_{\mathrm{p}+\mathrm{s}}^{\prime}=m_{\mathrm{p}} \frac{1-\rho_{\mathrm{air} 2} / \rho_{\mathrm{p}}}{1-\rho_{\mathrm{air} 2} / \rho_{\mathrm{cal}}}+m_{\mathrm{s}} \frac{1-\rho_{\mathrm{air} 2} / \rho_{\mathrm{s}}}{1-\rho_{\mathrm{air} 2} / \rho_{\mathrm{cal}}}$

Again, note that $m_{\mathrm{s}}=\rho_{\mathrm{s}} V_{\mathrm{p}}$. From the above equations one can obtain $\rho_{\mathrm{s}}$ :

$m_{\mathrm{p}+\mathrm{s}}^{\prime}-m_{\mathrm{p} 2}^{\prime}=\rho_{\mathrm{s}} V_{\mathrm{p}} \frac{1-\rho_{\mathrm{air} 2} / \rho_{\mathrm{s}}}{1-\rho_{\text {air } 2} / \rho_{\mathrm{cal}}}$

$\rho_{\mathrm{s}}=\frac{m_{\mathrm{p}+\mathrm{s}}^{\prime}-m_{\mathrm{p} 2}^{\prime}}{V_{\mathrm{p}}}\left(1-\rho_{\mathrm{air} 2} / \rho_{\mathrm{cal}}\right)+\rho_{\text {air } 2}$
Substitution of $V_{\mathrm{p}}$ yields the analytical solution to the pycnometer challenge:

$\rho_{\mathrm{s}}=\frac{m_{\mathrm{p}+\mathrm{s}}^{\prime}-m_{\mathrm{p} 2}^{\prime}}{m_{\mathrm{p}+\mathrm{w}}^{\prime}-m_{\mathrm{p} 1}^{\prime}} \times\left(\rho_{\mathrm{w}}-\rho_{\text {air } 1}\right) \times \frac{1-\rho_{\text {air } 2} / \rho_{\text {cal }}}{1-\rho_{\text {air } 1} / \rho_{\text {cal }}}+\rho_{\text {air } 2}$

This expression yields the density $\rho_{\mathrm{s}}$ in a single step which is not only more convenient but also enables straightforward estimation of the uncertainty.

$$
\begin{aligned}
\rho_{\mathrm{s}}= & \frac{15.1242-10.0348}{15.0216-10.0348} \times(997.880-1.18073) \mathrm{kgm}^{-3} \\
& \times \frac{1-1.17990 / 8000}{1-1.18073 / 8000}+1.17990 \mathrm{kgm}^{-3} \\
= & 1018.39 \mathrm{kgm}^{-3}=1.01839 \mathrm{~g} \mathrm{~mL}^{-1}
\end{aligned}
$$

This result is identical with that obtained from the iterative approach.

When sufficient amounts of sample solution are available, measurement of the density can be further simplified. The sample can be used to rinse the pycnometer directly after calibration with pure water. This eliminates the need for the drying of the pycnometer (and equilibration to room temperature). During such an experiment, the ambient conditions (air density) will not change significantly, resulting in $\rho_{\text {air } 1}=$ $\rho_{\text {air } 2}=\rho_{\text {air }}, m_{\mathrm{p} 1}^{\prime}=m_{\mathrm{p} 2}^{\prime}=m_{\mathrm{p}}^{\prime}$, and a more elegant equation:

$\rho_{\mathrm{s}}=\frac{m_{\mathrm{p}+\mathrm{s}}^{\prime}-m_{\mathrm{p}}^{\prime}}{m_{\mathrm{p}+\mathrm{w}}^{\prime}-m_{\mathrm{p}}^{\prime}} \times\left(\rho_{\mathrm{w}}-\rho_{\mathrm{air}}\right)+\rho_{\mathrm{air}}$

Acknowledgements The authors would like to thank Michael Koch (University of Stuttgart, Germany) who was the first to point out the elegant analytical solution.

\section{References}

1. Spieweck F, Bettin H (1992) Tech Mess 59:285-292

2. Dieterle M (2011) http://ap.physik.unibas.ch/PDF/Manuals/English/ Experiment_03.pdf

\section{Further Reading}

1. Rienitz O, Pramann A, Pape C (2013) Anal Bioanal Chem 405:56275628 